\title{
Prospects for the Development of Geothermal Energy Supply
}

\author{
V.A. Stennikov ${ }^{1 *}$, S.Batmunkh ${ }^{2}$, P.A.Sokolov ${ }^{1}$
}

\begin{abstract}
${ }^{1}$ Melentiev Energy Systems Institute of Siberian Branch of Russian Academy of Sciences, Irkutsk, Russia
${ }^{2}$ Mongolia Science and Technology University
\end{abstract}

\begin{abstract}
The paper addresses methodological and technological issues of building environmentally friendly and efficient energy supply based on geothermal energy sources. Geothermal potential in the world, accentuating that in Russia (areas of the Baikal natural territory) and Mongolia, is analyzed considering the possibility of its implementation in the thermal power industry.
\end{abstract}

Geothermal areas of Central Mongolia are characterized by increased heat flows and occurrences of thermal waters. The most promising thermal spring occurrences are the Shivert, Shargalzhuut, Tsenkher, Otgontenger, and Khuzhirt, to name some of them. Currently, the thermal energy potential of the Khangai arched uplift in Central Mongolia is employed to heat industrial, agricultural, and civil facilities. There are also plans to consider the possibility of largescale employment of thermal waters of the region for electricity generation.

An example of using geothermal waters for electricity generation is given, and the possibility of establishing a heating system in the city of Tsetserleg based on a geothermal heat pump unit with a wind power plant is assessed.

Index Terms: geothermal energy, heat pumping stations, heat supply, geothermal power plant, integrated energy system

\footnotetext{
${ }^{*}$ Corresponding author.

E-mail: sva@isem.irk.ru
}

http://dx.doi.org/10.38028/esr.2021.03.0003

Received September 29, 2021. Revised October 10, 2021.

Accepted November 05, 2021. Available online November 28, 2021.

This is an open access article under a Creative Commons Attribution-NonCommercial 4.0 International License.

C) 2021 ESI SB RAS and authors. All rights reserved.

\section{INTRODUCTION}

The research and practical use of geothermal resources have been increasingly attracting the attention of the world community lately. They seem relevant for both the study of resource reserves and their extraction and the expansion of the scope of practical application. Depending on the temperature difference, geothermal resources can be used to generate either electricity or heat. The greatest field of geothermal heat application as hot water is heating, which requires a lower heating agent temperature. Expansion of such heat application becomes possible with the development of the market for nonconventional equipment and its availability. A heat pump is often installed to increase the temperature potential in the heating system to coordinate the temperature charts of the heat carrier supplied and used by consumers. Renewable energy sources can be employed in integrated sources with gas turbines and fossil fuel cogeneration plants. This paper considers their design solutions and possible use.

\section{Potential OF GEOTHERMAL RESOURCES IN THE WORLD}

One of the current trends in global renewable energy development is the involvement of geothermal energy resources in the energy supply. The total installed capacity of geothermal power plants is currently $16 \mathrm{GW}$. It is certainly a low value compared to the capacity of other renewable energy sources, not to mention fossil fuel energy. In many regions, however, only the energy of the Earth can provide the population with cheap heat and electricity. The potentialities of different types of geothermal energy resources by region are shown in Table 1 [1].

According to Rystad Energy (Rystad Energy is an independent energy research and business intelligence company providing consultancy services, an located in Oslo, Norway), the industry will receive $\$ 25$ billion in investments over the next five years and increase its 
TABLE 1. Potential of different types of geothermal sources in the world

\begin{tabular}{lccc}
\hline \hline \multirow{2}{*}{ Continent } & \multicolumn{3}{c}{ Geothermal source type } \\
\cline { 2 - 4 } & \multicolumn{2}{c}{ High-temperature, used for power generation, TJ/year } & $\begin{array}{l}\text { Low-temperature, used as heat, } \\
\text { TJ/year (lower limit) }\end{array}$ \\
\cline { 2 - 4 } & Conventional technologies & Conventional and binary technologies & $>370$ \\
\hline Europe & 1830 & 3700 & $>320$ \\
\hline Asia & 2970 & 5900 & $>240$ \\
\hline Africa & 1220 & 2400 & $>120$ \\
\hline North America & 1330 & 2700 & $>240$ \\
\hline Latin America & 2800 & 5600 & $>110$ \\
\hline Oceania & 1050 & 2100 & $>1400$ \\
\hline World potential & 11200 & 22400 & \\
\hline \hline
\end{tabular}

TABLE 2. Geothermal power plants in Russia (2017)*

\begin{tabular}{|c|c|c|c|c|c|c|}
\hline $\begin{array}{l}\text { Name of } \\
\text { geothermal } \\
\text { power plant }\end{array}$ & $\begin{array}{l}\text { Installed } \\
\text { capacity }\end{array}$ & $\begin{array}{c}\text { Generated electricity, } \\
\text { MWh }\end{array}$ & $\begin{array}{l}\text { Year of commissioning } \\
\text { the first unit }\end{array}$ & $\begin{array}{c}\text { Year of } \\
\text { commissioning the } \\
\text { last unit }\end{array}$ & Owner & Location \\
\hline Mutnovskaya & 50.0 & 329180 & 2003 & 2003 & $\begin{array}{c}\text { JSC } \\
\text { "Geoterm" }\end{array}$ & $\begin{array}{c}\text { Kamchatka } \\
\text { Territory }\end{array}$ \\
\hline Pauzhetskaya & 12.0 & 42896 & 1966 & 2006 & $\begin{array}{c}\text { JSC } \\
\text { "Geoterm" }\end{array}$ & $\begin{array}{c}\text { Kamchatka } \\
\text { Territory }\end{array}$ \\
\hline $\begin{array}{l}\text { Verkhne- } \\
\text { Mutnovskaya }\end{array}$ & 12.0 & 62876 & 1999 & 2000 & $\begin{array}{c}\text { JSC } \\
\text { "Geoterm" }\end{array}$ & $\begin{array}{c}\text { Kamchatka } \\
\text { Territory }\end{array}$ \\
\hline Total & 74 & 434952 & & & & \\
\hline
\end{tabular}

* - based on the data of $6 \mathrm{TP}$

capacity to $24 \mathrm{GW}$, which will lead to large-scale drilling operations and positively affect the workload of oil and gas service companies. Whereas the number of wells drilled in 2019 was more than 220 , in 2025 , this figure will grow to 400 [2]. Preparation of wells accounts for up to 40 percent of the costs of a geothermal plant, whereas the other part is the costs of surface infrastructure.

In general, more than 60 countries use geothermal energy in economic activity around the world. The same number of countries conduct research and experiments on its use. Geothermal sources, for example, meet a third of Iceland's energy demand and account for 27 percent of the Philippines' energy production.

\section{DEVELOPMENT OF GEOTHERMAL ENERGY SUPPLY IN RUSSIA}

Russia is not among the leaders in harnessing geothermal and renewable energy in general (wind, solar, and earth heat). In 2020, their share in the country's energy balance was no more than 1 percent. As mentioned above, the world's total installed capacity of geothermal power plants in 2020 exceeded 16.0 GW. In Russia, the capacity of geothermal power plants is $74 \mathrm{MW}$, which is also less than one percent in the capacity structure after decommissioning the two geothermal power plants on the Kuril Islands of the Sakhalin Region (in 2010, this figure was $81 \mathrm{MW}$ ) [3].

At the same time, the geothermal sources in Russia seem to be a rather promising strand and can be a serious alternative to fossil fuels according to economic and environmental criteria. The technical potential of geothermal resources is about 100 million t.c.e./year, and the economic potential reaches 30 million t.c.e./ year.

The geothermal energy reserves in Russia are tremendous. According to expert estimates, they are 10-15 times higher than the reserves of fossil fuels in the country. There are geothermal energy reserves throughout almost the entire country, with temperatures ranging from 30 to $200{ }^{\circ} \mathrm{C}$. About 4000 wells have been drilled to a depth of $5000 \mathrm{~m}$, which allows switching to large-scale adoption of the most advanced technologies for local geothermal heat supply. Given that the wells already exist, energy production in most cases proves to be an economically efficient technology [4].

Despite the high potential, most geothermal sources in Russia are located economically irrationally. The Kamchatka Territory, Sakhalin Island, and the Kuril Islands are characterized by poor infrastructure development, high seismicity, hard terrain, and scarce population, which is justified by the lack of fuel resources and their complicated delivery scheme (Table 2).

Currently, three geothermal power plants (Paratunskaya, Mendeleevskaya (under reconstruction), and Okeanskaya) are removed from service.

The geothermal resources of the Krasnodar Territory, Stavropol Territory, and the Kaliningrad Region, which have reserves of thermal waters with a temperature up to $1100{ }^{\circ} \mathrm{C}$, are of much greater interest. There are also geothermal energy reserves in Chukotka, including those 


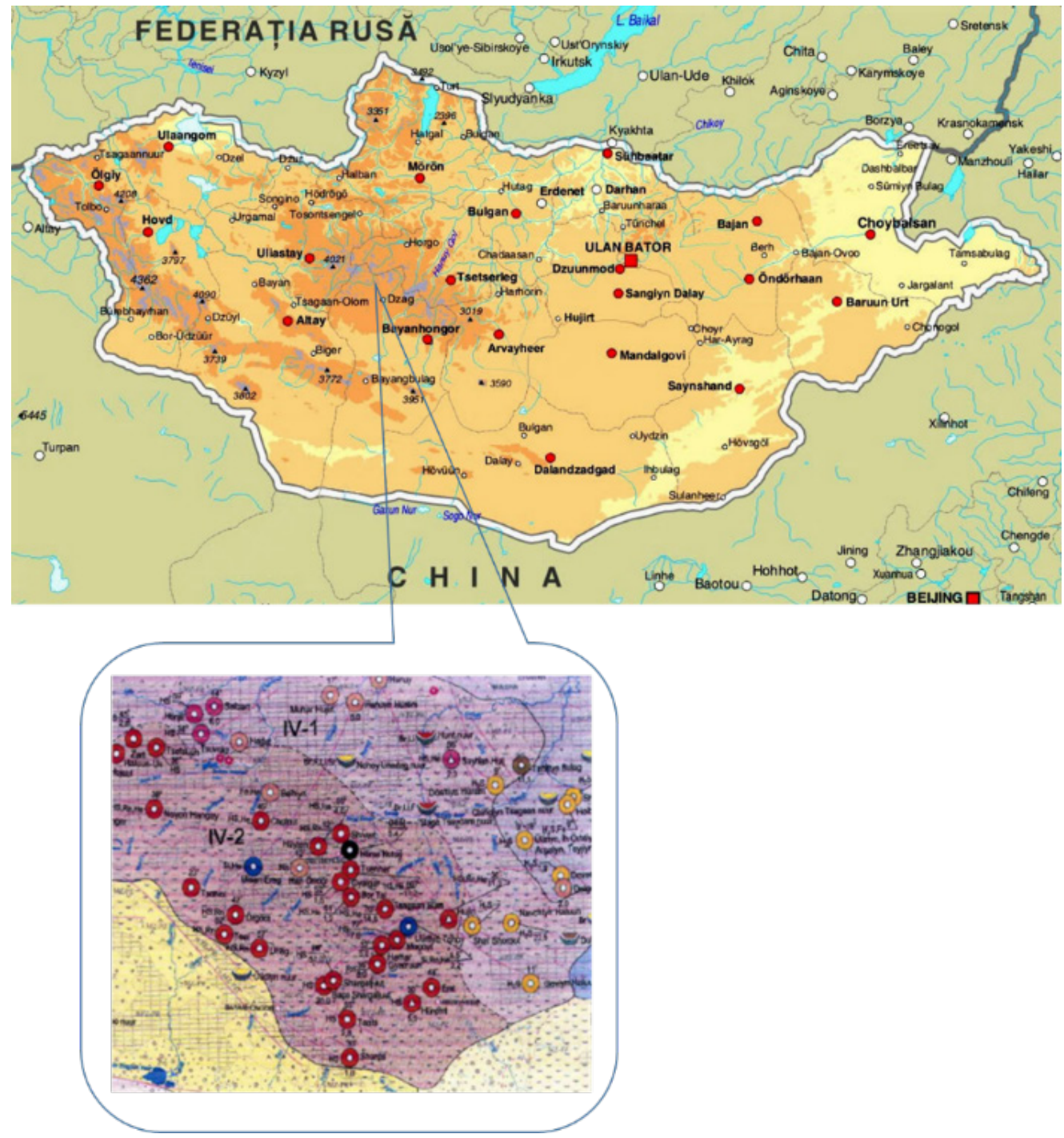

Fig.1. Map of Mongolia, Khangai hydrothermal system.

already discovered that can be actively used to supply energy to nearby settlements.

In the North Caucasus, there are well-studied geothermal deposits located at a depth of 300 to $5000 \mathrm{~m}$, with a temperature in the reservoir ranging from 70 to 1 $800{ }^{\circ} \mathrm{C}$. Geothermal resources have been used here for a long time for heating and hot water supply in agriculture, industry, and everyday life. For example, today, more than 30 percent of the housing stock in Dagestan is heated and supplied with hot water from geothermal sources, and this figure can rise to 70 percent.

Currently, about fifty geothermal deposits have been explored in Russia. Their use for geothermal energy development requires stimulating motivation and conditions for attracting investments. The introduction of geothermal energy into the energy balance of the country will, on the one hand, increase its energy security, and on the other hand, reduce the negative environmental impact compared to the conventional sources [5].

\section{GEOTHERMAL RESOURCES IN THE BAIKAL TERRITORY OF RUSSIA}

The hydrogeological region of the Baikal rift zone is one of the world's hugest rift zones holding numerous thermal springs (up to 60 springs). The depth of the thermal waters varies from $750 \mathrm{~m}$ to $2900 \mathrm{~m}$, the water temperature of the springs is 20 to $82{ }^{\circ} \mathrm{C}$, the flow rate is 1 to $85 \mathrm{l} / \mathrm{s}$, the salinity rarely reaches one $\mathrm{g} / \mathrm{l}$. The largest and most heated springs are Alginsky, Allinsky, Bauntovsky, Garginsky, Goryachinsky, Gusikhinsky, Insky, Kotelnikovsky, Kuchigersky, Mogoisky, Pitatelevsky, Umkheisky, Khakussky, Cheloleksky, to name some of them [6].

There are four most noticeably distinguished such hydromineral areas in the territory of the Baikal region (Torgashina MA Mineral springs of the Republic of Buryatia). These are East Sayan (thermal and cold carbonic waters), Baikal (nitrogen and methane thermal waters), Selenginskaya (cold non-carbonated radon waters), and Daurskaya (cold carbonic and radon waters) regions.

The maximum heat flow in the territory under 


\section{Thermal water source $\mathrm{T}=86^{\circ} \mathrm{C}$}

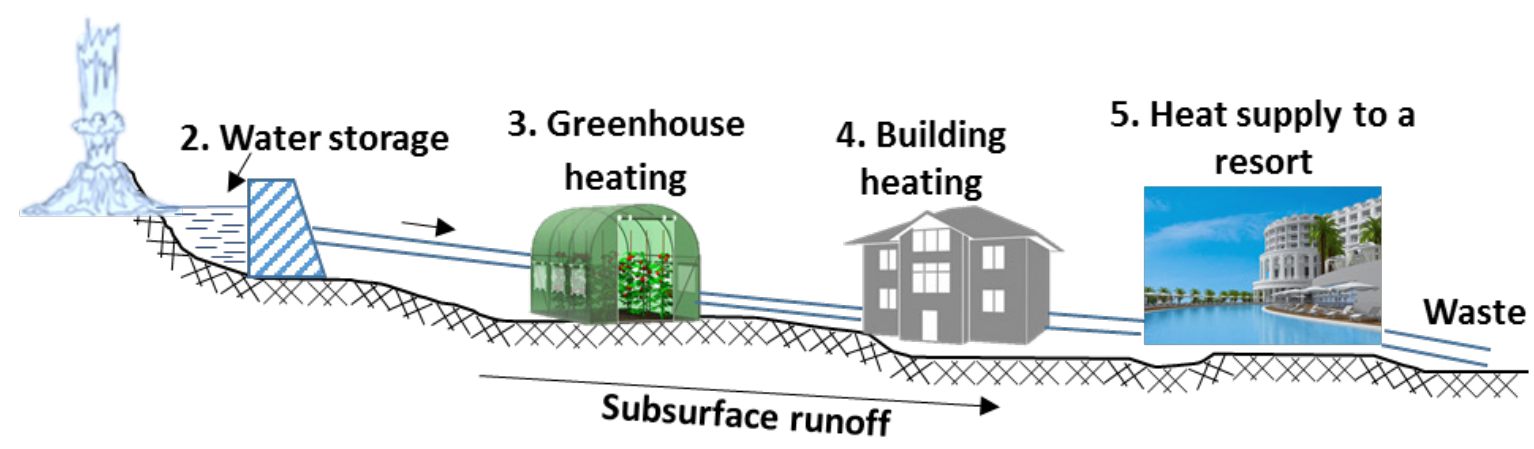

Fig.2. A diagram of a heat supply system based on a geothermal source.

consideration falls on the northern part of the Barguzin depression, in the area of the Allinsky, Kuchigersky, and Umkheisky thermal springs. However, the water temperature for these sources differs significantly because thermal springs are diluted by surface and ground waters due to fracture and vein formations.

\section{GEOTHERMAL RESOURCES IN THE REPUBLIC OF MONGOLIA}

Over the past two decades, researchers have conducted general studies regarding the geothermal conditions in Eastern Siberia and Mongolia, including the southern part of the Siberian Platform, the Baikal rift zone, the Baikal fold region, and Mongolia (four areas differing in geological and tectonic conditions). The structure of the continental crust in the provinces of Mongolia is highly heterogeneous - its age varies from the early Riphean to the late Cenozoic era. Nearly 43 geothermal sources have been discovered to date in the country, but their use is very limited [7].

Reserves of thermal springs in Mongolia (in particular, in the Khangai open-pit mine) significantly exceed the energy demand of consumers. Fig. 1 shows a map of Mongolia with a dedicated zone of geothermal sources, which has prerequisites for switching from boilers running on fossil fuel to thermal power plants operating on geothermal energy to provide heating to consumers.

It is worth noting that the thermal water (TW) parameters depend on several factors:

- the depth of extraction, which is associated with capital expenditures for the construction of well;

- the location of the wells and the distance of the heating agent transportation to the consumer;

- geothermal parameters of thermal water (flow rate, temperature, and pressure at the outlet, mineralization of thermal water, chemical composition, and others).

Animportant parametercharacterizing the thermodynamic efficiency of a thermal source is the temperature gradient for every $100 \mathrm{~m}$ of depth, which is very important to arrange heat supply to local and dispersed consumers.
When extracting thermal water of the said well outlet temperatures, the temperature can vary significantly depending on the well drilling depth. The range may depend on the well location and other hydrogeological conditions.

Natural resources of thermal waters on the territory of the Khangai arch in Mongolia are estimated at 17044 $\mathrm{m}^{3} /$ day. Hydrothermal fluids emerging from the depths to the surface have a value of $1880.926 \mathrm{GJ} /$ day of energy potential.

Geothermal areas of Central Mongolia are characterized by increased heat flows, outlets, and deposits of thermal waters. The most promising areas for exploring hydrothermal waters are those that have experienced the intense influence of the newest tectonic movements and volcanism, mainly located in folded areas. Thermal waters here have local development and are of a fraction-vein type. The areas of the Khangai arched uplift, where the Shivert, Shargalzhuut, Tsenkher, Otgontenger, Khuzhirt deposits, and other hydrotherms are located, should be considered the most productive ones $[8,9]$. Their operational thermal water reserves are approved by the State Commission for Reserves in the highest categories (A, B, C). At present, in Central Mongolia, the heat and power potential of the Khangai arched uplift is used insignificantly for heat supply to industrial, agricultural, and civil facilities, which is why the possibility of an integrated large-scale use of the region's thermal waters is considered.

The proposed schematic diagram of a heat supply system intended for heating greenhouses, and providing heating and hot water to residential buildings and health resorts is shown in Fig. 2.

Thermal waters of granite massifs in the region are widely distributed but limited in resources that do not exceed $3-5 \mathrm{l} / \mathrm{s}$ or amount to $10 \mathrm{l} / \mathrm{s}$ in exceptional conditions, with their (outlet) temperatures about $90-96{ }^{\circ} \mathrm{C}$.

Geothermal resources of Mongolia can be divided into four types in terms of their use: balneology and sanatorium 


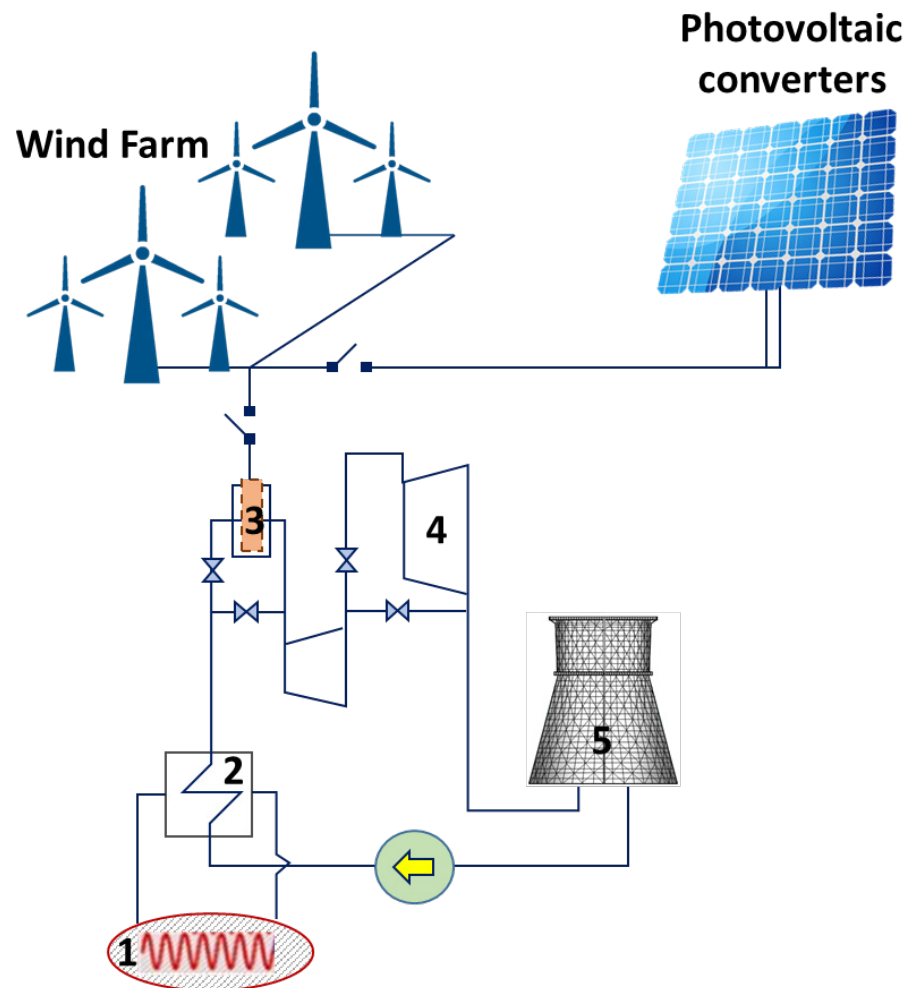

Fig. 3. Combination of GeoPP with WPP and PVP: 1 - geothermal heat source; 2 -steam generator; 3 - low-temperature heating elements; 4 parts of high and low-pressure steam turbine; 5 - «dry» cooling tower as condenser.

services, heat supply, agriculture, power supply. Heat supply based on thermal waters in Mongolia was provided mainly through the construction of small heating facilities, hot water supply, and balneology. In 2016, Japanese specialists, for the first time, installed a plant at the Tsenkher resort and produced electricity for hotel facilities [10].

The term «thermal energy water» usually means natural hot groundwater that can be used in the national economy as a source for heat or thermal energy production. At the same time, the main criterion for classifying thermal water as a thermal energy resource is its temperature. Like other types of groundwater used in the national economy, thermal waters are minerals and belong to the complex raw material to be used not only for medicinal purposes but also as a source of extraction of valuable elements and their compounds for various technological needs.

Water used for thermal energy has a temperature above $35-40{ }^{\circ} \mathrm{C}$. In this case, the lower value of the water temperature for heating the protected ground during balneological procedures is $35^{\circ} \mathrm{C}$, and the lower limit of the water temperature for hot water supply is $40-45^{\circ} \mathrm{C}$. Based on the experience of using thermal waters, they are divided into low- and medium-potential ones. Medium-potential waters (with a temperature of $70-100{ }^{\circ} \mathrm{C}$ ) are used for the needs of heat supply. These waters can be effectively used for heat supply to industrial, agricultural, and municipal facilities. The efficiency of using such waters for heating can be significantly enhanced by equipping heat consumers with heating and ventilation systems optimized for low and medium-potential heating agents, including their combination with heat pumps.

\section{CURRENT CHALLENGES FOR GEOTHERMAL ENERGY}

There is a great deal of positive experience in using geothermal energy for energy supply to consumers. However, some issues limit the scope of this renewable energy resource and need resolving. The most significant of them are:

1. A relatively low temperature potential of a heating agent, which significantly depends on geothermal conditions of the area and the depth of occurrence of a productive natural or artificial reservoir. The temperature of the heating agent supplied to the consumer can be controlled by raising it in peak boiler houses or with heat pumps, which increases the costs and decreases the competitiveness of geothermal power plants.

2. The limited range of the heating agent transport due to its low heat content and high cost of heat pipelines for energy transmission over long distances.

3. The difficulty in heat storage. Heat storage in the form of hot water in tanks is possible only to smooth out the temporary irregularity of the daily heat load curves or in the event of a short-term shutdown of the geothermal circulation system [11]. 


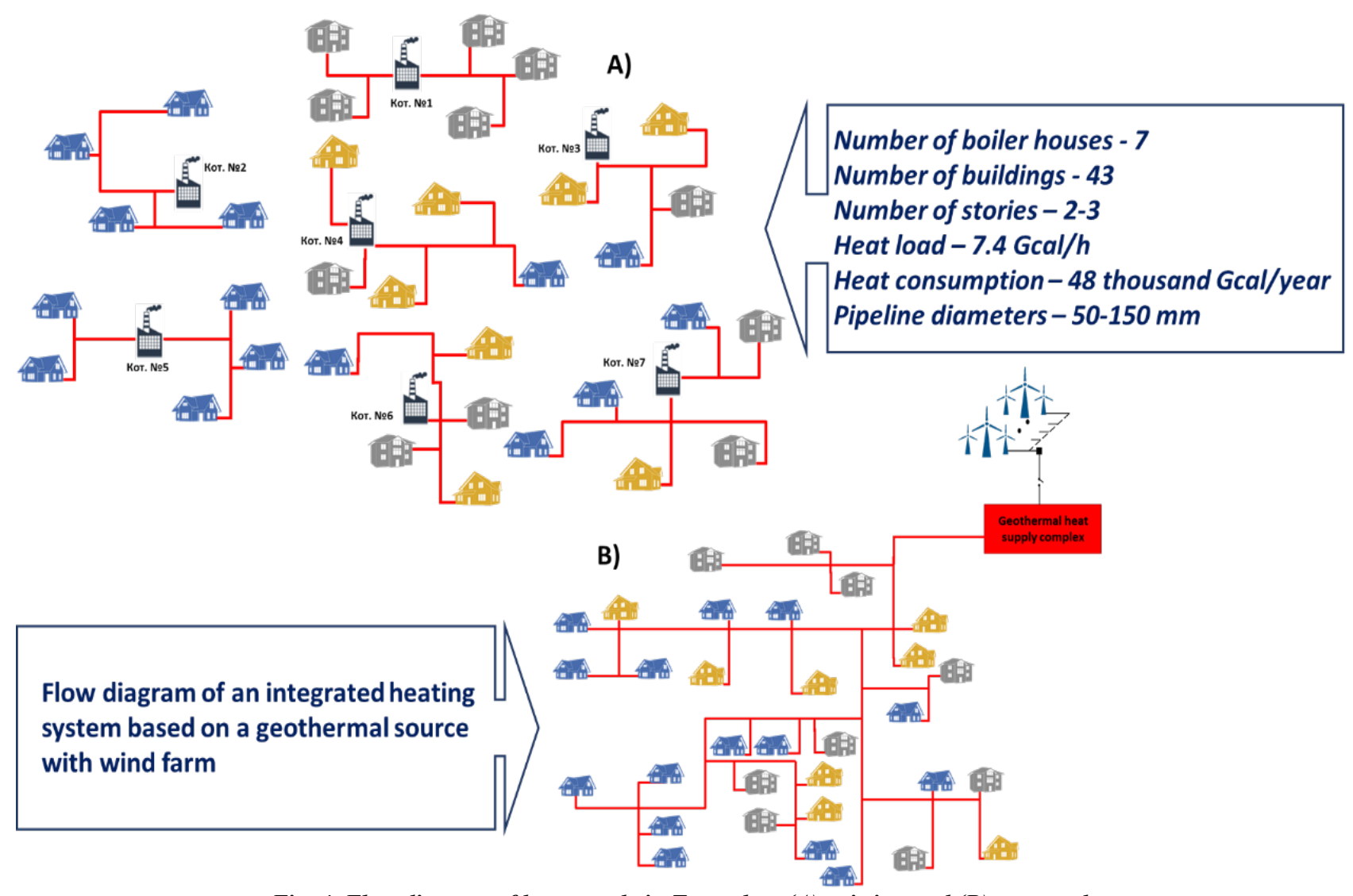

Fig. 4. Flow diagram of heat supply in Tsetserleg: (A) existing and (B) proposed.

4. Large amounts of work and costs due to the lack of effective technologies to explore and develop new deposits.

5. Significant content of minerals, which leads to high levels of salt deposition and corrosion of materials and equipment.

6. Low heat content of geothermal resources, which complicates their use for electricity generation.

7. Substantial environmental impact.

The above issues of using geothermal energy suggest that its practical use requires considerable capital investment in the construction of wells. High mineralization of thermal waters leads to corrosion that destroys the structures of geothermal power plants, which is why it is necessary to develop systems for periodic and constant cleaning of pipes, pumps, and shut-off valves, which increases the cost of operating geothermal plants.

\section{CREATION OF INTEGRATED SYSTEMS TO IMPROVE THE EFFICIENCY OF A GEOTHERMAL POWER PLANT}

The increase in the efficiency of geothermal heat and expansion of its application scope can be achieved by integrating double-circuit geothermal power plants (GeoPPs) [12] with wind power plants (WPP) and solar plants based on photovoltaic converters (PVP). This integration allows additional steam superheating for a steam turbine unit (STU) operating on a working medium with a low boiling point. The use of low-quality electricity from WPP and PVP for superheating steam in low-temperature heating elements (HE) eliminates many problems that arise when they are directly connected to the power system (Fig. 3) [13-17].

The efficiency of such a geothermal power plant increases to a boost in the efficiency and power resulting from the rise in upper temperature of the STU cycle and a decrease in the lower temperature of the cycle (possibly to negative values) in winter since admissible steam humidity in the last turbine stages is provided even under increased degrees of its expansion. Thus, the temperature difference between the geothermal source and the surrounding air is more fully used. This plant can be equipped with a low-pressure turbine part (LPP), which is used only in the winter period, by analogy with T-type turbines, in which LPP is used for condensing power generation. The STU operates at sliding steam pressure at the bottom of the thermodynamic cycle (at the turbine outlet), as in conventional steam turbine TPPs working at sliding steam pressure at the top (at the turbine inlet). Operating conditions of the plant are regulated by redistributing the WPP/PVP electricity among heating elements of GeoPP, peak electric boiler houses, and energy storage devices if the latter are available.

Recently, there has been a significant decrease in the cost of PV plants. However, this decrease is insignificant 


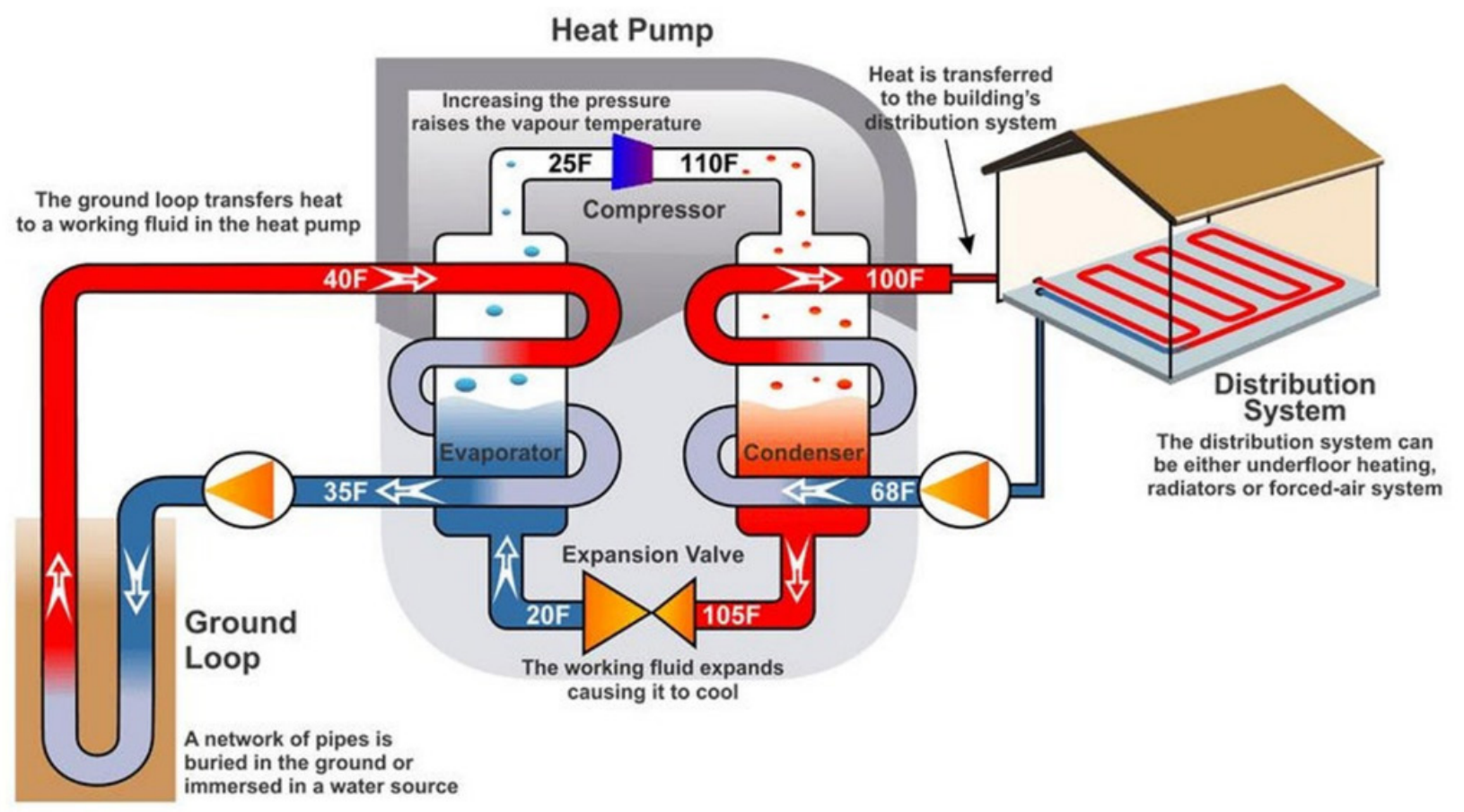

Fig. 5. Flow diagram of a heat pump using thermal waters.

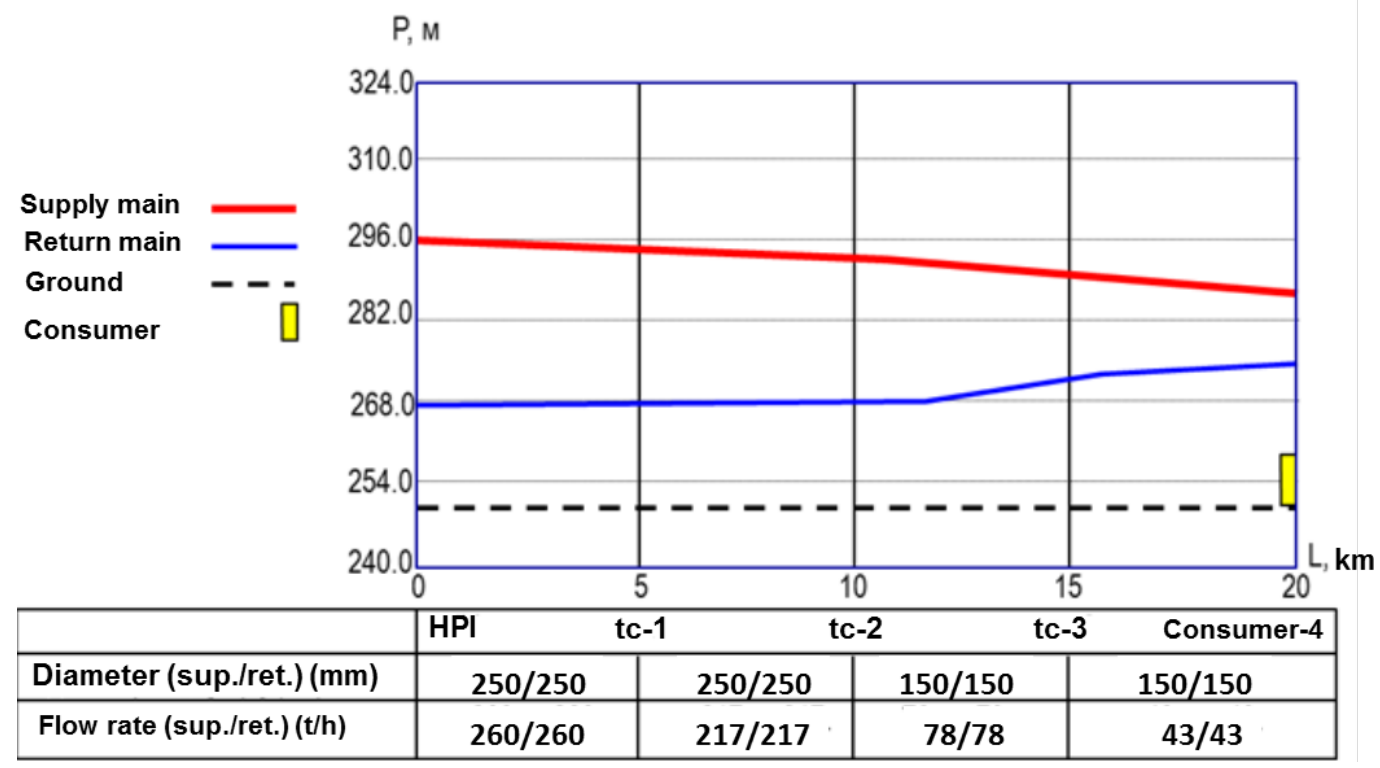

Fig. 6. Piezometric graph between HP valve vaults, consumer 4.

due to the need to have expensive rectifiers, inverters, transformers, switches, and others. Since the proposed diagram suggests that GeoPP should replace storage, inverter, and step-up transformer, it is logical to include PVP in the GeoPP through STU. Solar and wind energy is most efficiently used together in one power complex since the change in their active operation usually occurs in antiphase. When GeoPP operates on steam, the erosion effect on turbine blades goes down due to its overheating with a corresponding decline in humidity. Working medium (low-temperature or water vapor) can be tapped from the turbine extractions to the heating system water heaters.

The use of heat pumps in geothermal power supply technology seems to be an effective measure to increase the efficiency and scope of application. Heat pumping units (HPUs) can significantly reduce either the consumption of thermal water from debit wells or their number (all other things being equal). Thus, the combined thermal power plant based on a thermal source and an HPU may become more technically accessible for heat supply according to the temperature chart of the heat output (depending on the outside air temperature). 
TABLE 3. Payback period of the heat pump-based heating system in Tsetserleg versus the distance to the geothermal source

\begin{tabular}{ccccc}
\hline \hline Option No. & $\begin{array}{c}\text { Distance from the } \\
\text { source to the city, } \mathrm{m}\end{array}$ & $\begin{array}{c}\text { Cost of the pipeline network, } \\
\text { given the intracity networks, } \\
\text { RUR mln }\end{array}$ & $\begin{array}{c}\text { The cost of HPU with a } \\
\text { pipeline network, RUR mln }\end{array}$ \\
\hline 1 & 0 & 9.2 & 68.5 & 99 \\
\hline 2 & 1300 & 39.7 & 135.6 & 211.8 \\
\hline 3 & 2500 & 76.3 & 288.1 \\
\hline 4 & 5000 & 152.5 & 3.6 \\
\hline 6
\end{tabular}

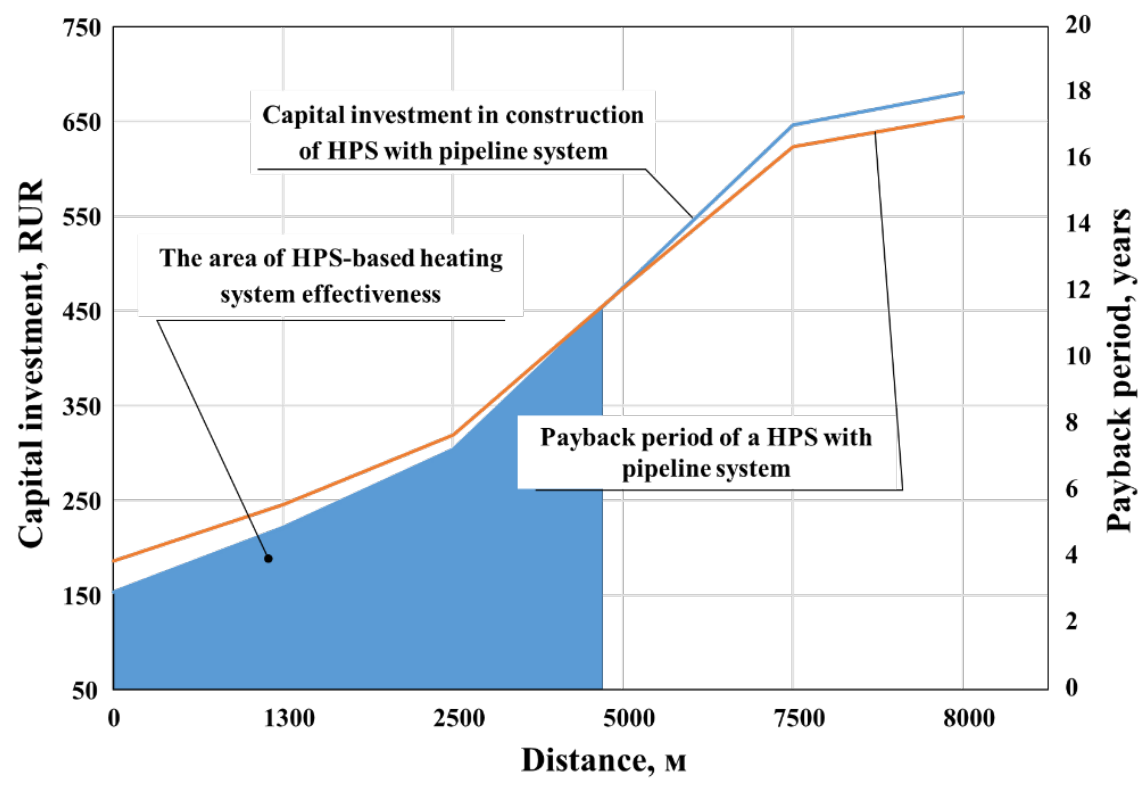

Fig. 7. Investment and payback period for HPS with a pipeline network.

A feasibility study on the efficiency of heat pumping stations (HPS) for heat supply purposes should consider that HPS characteristics should be calculated for the longest period of low ambient temperatures in the region. With this approach, the consumption of thermal water and electricity for the drive of the heating pump motor will lead to the overestimation of cost indices, which may not always be justified. For example, if the continuous duration of low temperatures does not exceed 10-15 days.

Heat pumps can provide heat energy needs with specified parameters both for an individual consumer (autonomous) and for local group consumers (4-10 private buildings) or district heating (for urban-type settlements).

\section{GEOTHERMAL HEAT SUPPLY SYSTEM DESIGN}

Within the cooperation between the Siberian Branch of the Russian Academy of Sciences and the Mongolian Academy of Sciences, the research team considered several localities in Siberia of the Russian Federation and Mongolia that were supposed to be provided with geothermal power. The city of Tsetserleg, with low-efficiency coal-fired boilers (with geothermal deposits located in its area), proved to be the most preferable.

At present, the city receives heat from 7 coal-fired boiler houses located in the city center (Fig. 4), which significantly pollutes the environment. The distance of coal transportation is $253 \mathrm{~km}$. The heating system is dead-end. There are 4-6 buildings connected to each boiler house, with the tallest building $8.4 \mathrm{~m}$ high. The diameter of the heat network pipelines varies from 50 to $150 \mathrm{~mm}$.

The annual heat consumption of the city is about 47.6 thousand Gcal/year. Construction of HPS running on geothermal water and its commissioning will provide thermal energy for heating, ventilation, and hot water supply to the city.

The heating system of Tsetserleg can be converted to a geothermal system with the help of an HPS, which includes four heat pumps connected in series. In this case, three circulation circuits of heating agents are formed (Fig. 5), including:

1 - geothermal water;

2 - working fluid of the heating pump;

3 - network water of the city heating system.

Calculations of the heat supply system from a single source show that such a system has good operability but requires a relatively considerable investment in the heat pipeline construction from the geothermal sources «Tsenkher» and «Shivert» to the city, $15 \mathrm{~km}$ and $20 \mathrm{~km}$ 
long, respectively. Fig. 4 shows a diagram of the existing heat supply system of the city and a diagram of heat supply from a single geothermal source with a WPP.

The piezometric graph (from this source to the most distant urban consumer) obtained from the calculation is shown in Fig. 6. It testifies to the feasibility of the thermalhydraulic conditions of such a heat supply system.

A long-range heating agent transport significantly increases investment in the geothermal heat supply system and leads to insufficient competitiveness versus coal heat sources.

In recent years, new large reserves of geothermal resources with a relatively high water temperature, sufficient for heating, have been discovered. Some of them are located at a shorter distance from the city (about $8 \mathrm{~km}$ ), and others are located directly on its territory. The close location of geothermal sources from the heat consumption centers can significantly reduce investment in the heat networks construction and enhance system efficiency. New geothermal sources have good technical and economic indices:

- considerable resources at the accessible depth;

- the proximity of deposits to the consumption center;

- transportability without significant heat loss.

Relatively shallow drilling of wells (50-100 m) and high water temperature contribute to a significant reduction in the cost of the geothermal heating system for the city.

Pipelines with polyurethane foam insulation were considered for heat transportation in the heating system of Tsetserleg. They have low heat losses (within $2 \%$ ), high reliability, and guaranteed service life of up to 50 years. These factors make it possible to reduce the cost of maintaining heat pipelines by nine times and cut the capital expenses of constructing heat networks by 1.2 times compared to the traditional construction of pipelines. The construction time of heat networks with polyurethane foam pipelines laid without channels is reduced by $2.5-3$ times.

Systems of operational remote control (ORC) to be installed in pipelines with polyurethane foam insulation allow additional remote monitoring of the heating main state to prevent accidents and their prompt elimination. The ORC system sensors, based on time-domain reflectometers, detect the place of occurrence of a steel pipe defect with an accuracy of one meter.

Depending on the distance between the geothermal source and the heat load center, investment in the pipeline network can vary from RUR 9.2 to 245 million.

The efficiency of a heating system to be based on a geothermal source will be determined by a decrease in the fuel component in the heat cost price.

Table 3 shows payback periods for the heating system of the city of Tsetserleg versus the distance between the geothermal source and the heat load center.

Calculations show that the closer the geothermal source to the load center, the more efficient is a heating system

\section{based on it.}

Fig. 7 shows graphically the relationship between the costs and payback periods depending on the distance between the geothermal source and load center, along with the efficiency zone of adopting the HPS-based heating system.

With a payback period of up to 8 years, it is efficient to transport geothermal energy at a distance of up to $4 \mathrm{~km}$ from the heat load center.

Heat pumping station using geothermal heat will reduce harmful emissions of SOx, NOx, particulate matter, and fluoride compounds, which will decrease the environmental impact significantly. The improvement in the environmental situation, displacement of expensive imported coal will pay off the investment and make this project economically attractive.

\section{CONCLUSIONS}

The generalization of the experience of using heat pump technology in the world practice and the technical and economic calculations performed in this work to assess the HPS feasibility for heat supply to consumers allowed formulating the following:

- for geothermal energy to be used in heating and hot water supply, it is advisable to employ heat pumps. They allow the use of sources with low-temperature geothermal water, which makes it possible to involve not only large high-potential geothermal deposits but also local low-potential sources of geothermal waters located near the consumer;

- heat pumps fit well into the existing heat supply system, as they are environmentally friendly, reliable, safe, durable plants that can reduce both the consumption of geothermal water supplied from a well and the number of these wells (all other things being equal);

- inclusion of HPS in the geothermal heat supply system ensures the technical and economic availability of heat supply with the possibility of regulating thermal energy supply to consumers, according to the output temperature chart, depending on the outside air temperature;

- the HPS efficiency potential can be increased, and the scope of applying renewable resources in Mongolia and other territories can be expanded by involving wind energy in an integrated energy complex to be established.

- Assessing general situation in geothermal energy, it is worthwhile to note that despite the existing issues, it has seen significant advancement in recent years, which is largely due to the improvement in technologies and the expansion of the market for new equipment:

- the efficiency of geothermal sources rises significantly with their integrated use, which provides the completest implementation of the geothermal water thermal potential, including residual one, in various technological processes, and allows the production of 
valuable components contained in this water (iodine, bromine, lithium, cesium, sodium sulfate, boric acid, and many others) for their industrial use;

- the development and application of new effective methods of water purification from toxic compounds and metals continuously reduce capital costs of producing heat from geothermal sources;

- the geothermal resources of the Shivert, Shargalzhuut, Tsenkher, Otgontenger, Khuzhirt, and other deposits of the Khangai arched uplift are currently most promising for practical use. They can be widely employed in heating and hot water supply to resorts, various populated areas, including large cities, and in the development of greenhouse farms and balneological centers;

- the intermittent electricity from WPP and PVP for steam superheating can boost the efficiency of GeoPP by increasing the upper and average integral temperature of heat input in the cycle, enhance the efficiency and power of the power plant, reduce erosion damage to turbine blades, and extend the life of wells and deposits;

- the concept of an integrated power system removes technological restrictions on the level of wind and solar energy in power systems, which increases the environmental safety and economic viability of geothermal energy and makes it competitive in relation to conventional methods of electricity and heat generation. In addition, the integration of energy technologies helps reduce the consumption of fossil fuels, expands the use of renewable energy sources without the expensive batteries, and fosters the reduction of $\mathrm{CO} 2$ emissions without using expensive technologies for their disposal.

\section{REFERENCES}

[1] http://news-mining.ru/analitika/20769_perspektivybureniya--eto-geotermalnaya-energetika/

[2] https://eenergy.media/2020/10/29/geotermalnayaenergetika-pribavit-50-za-blizhajshie-5-let/

[3] https://www.c-o-k.ru/market_news/geotermalnayaenergetika-rastet

[4] https://www.rosteplo.ru/Tech_stat/stat_shablon. php?id=446\&p=2

[5] Yu. A. Leonova, "Development of renewable energy sources in Russia," Vestnik of Institute of Economic Research, no. 3 (15). pp. 126-133, 2019.

[6] Hydrogeology of the Republic of Buryatia. Available: https://clck.ru/UJAeG. Accessed on: Aug. 21, 2021.

[7] In-depth review of the investment climate and structure of the market in the energy sector of Mongolia, Energy Charter Secretariat, pp. 83, 2013.

[8] M. D. Khutorskoy, V. A. Golubev, S. V. Kozlovtseva et al., Thermal conditions of the subsoil of the MPR, V. I. Kononov, N. S. Zaitsev, eds. Moscow, Russia: Nauka, 1991, 126 p.
[9] D. Surmaazhav, A. G. Vakhromeev, G. M. Tolkachev, S. A. Sverkunov, N. N. Martynov, V. G. Zalivin, "Design and technology of drilling wells in difficult mining and geological conditions for the extraction of thermal waters," Bulletin of PNRPU. Geology. Oil and Gas Engineering and Mining, no. 4, pp. 335-343, 2019.

[10] D. Surmaazhav, "Thermal energy resources of thermal waters of central Mongolia," Advances in Current Natural Sciences, no. 9, pp. 106-112, 2020.

[11] E. I. Boguslavsky, "Economic assessment of geothermal resources," in Int. Symp. Problems of geothermal energy, Saint-Petersburg, Russia, 1995, vol. 1, pp. 86-96.

[12] Yu. P. Alekseev, S. N. Golubchikov, "Geothermal resources of Russia," Energy: Economics, Technology, Ecology, no. 3, pp. 42-44, 2004.

[13] S. V. Zharkov, "The use of wind energy in power supply systems of the northern regions of the Russian Federation," Thermal Engineering, no. 10, pp. 37-40, 2003.

[14] V. A. Stennikov, S. V. Zharkov, "Problems of WPP use in off-grid energy systems and possible ways to solve them", in Proceedings of the First International Forum "Renewable Energy. Ways to Improve Energy and Economic Efficiency REENFOR-2013”, Moscow, Russia, Joint Institute for High Temperatures of RAS, Oct., 22-23, 2013.

[15] V. A. Stennikov, S. V. Zharkov, "Wind power plants in power systems: problems and solutions," Energy and Fuel and Energy Complex, no. 5, pp. 46-47, 2014.

[16] V. A. Stennikov, S. V. Zharkov, P. A. Sokolov, "Application of geothermal sources in heat supply," Industrial Power Engineering, no. 4, pp. 50-54, 2014.

[17] V. A. Stennikov, S. V. Zharkov, "Unregulated electricity of wind power plants as a substitute for high-quality fuel at thermal power plants," Tyazheloe Mashinostroenie (Heavy Machine Building), no. 10, pp. 32-35, 2014. 


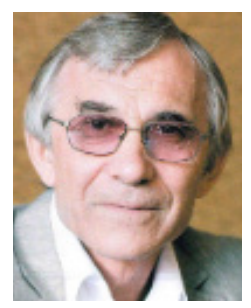

Valery Stennikov, Corresponding Member of the Russian Academy of Sciences, Professor, Director of Melentiev Energy Systems Institute, the Siberian Branch of the Russian Academy of Sciences (ESI SB RAS), Irkutsk, Russia. Valery Stennikov is the author and co-author of over 400 scientific publications. His research interests include systems research in energy, theory of hydraulic circuits, mathematical modeling, optimization methods, heat supply systems, district heating systems, cogeneration, reliability, energy efficiency, energy saving, intelligent energy systems.

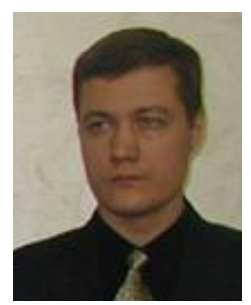

Pavel Sokolov, Lead Engineer, Laboratory of Heat Supply Systems, Melentiev Energy Systems Institute, the Siberian Branch of the Russian Academy of Sciences (ESI SB RAS), Irkutsk, Russia. Pavel Sokolov is the author and co-author of over 40 scientific publications. His research interests include energy systems, district heating systems, energy saving and energy efficiency, consumer, renewable energy.



Sereeterin Batmunkh, Academician of the Academy of Sciences of Mongolia, D.Sc. in Engineering, Professor, Honored Teacher of Mongolia, a prominent Mongolian scientist and teacher in the field of thermal physics and energy, who has contributed to the improvement of the heat and power supply to enterprises and cities by introducing advanced technologies to energy generating sources, production processes, training of highly qualified engineering and scientific personnel and the organization of fundamental and applied research in scientific institutions. 